\title{
Carbon microspheres decorated with iron sulfide nanoparticles for mercury(II) removal from water
}

\author{
Tibor Pasinszki ${ }^{1,2, *}$ (1) Melinda Krebsz ${ }^{2}$ (1), Deepak Chand ${ }^{1}$ (D), László Kótai ${ }^{3}$ (1), \\ Zoltán Homonnay ${ }^{2}$ (D), István E. Sajó ${ }^{4}$ (D), and Tamás Váczi ${ }^{5,6}$ (D) \\ ${ }^{1}$ Department of Chemistry, School of Pure Sciences, College of Engineering, Science and Technology, Fiji National University, \\ P.O. Box 7222, Nasinu, Fiji \\ ${ }^{2}$ Institute of Chemistry, Eötvös Loránd University, P.O. Box 32, Budapest 112 1518, Hungary \\ ${ }^{3}$ Institute of Materials and Environmental Chemistry, Research Centre of Natural Sciences, Hungarian Academy of Sciences, \\ P.O. Box 286, Budapest 1519, Hungary \\ ${ }^{4}$ János Szentágothai Research Centre, University of Pécs, Ifjúság u. 20, Pecs 7624, Hungary \\ ${ }^{5}$ Department of Mineralogy, Eötvös Loránd University, P.O. Box 32, Budapest 112 1518, Hungary \\ ${ }^{6}$ Wigner Research Centre for Physics, Hungarian Academy of Sciences, Konkoly-Thege Miklós út 29-33, Budapest 1124, Hungary
}

Received: 20 July 2019

Accepted: 11 September 2019

Published online:

26 September 2019

(C) The Author(s) 2019

\begin{abstract}
A new and simple method is developed to synthesize carbon microspheres decorated with iron sulfide nanoparticles for mercury ion removal from water. The synthesis is based on carbonizing polystyrene-divinylbenzene-based and iron(III) sulfate-loaded cation exchange resins between 500 and $1000{ }^{\circ} \mathrm{C}$. The phase composition, surface area, and morphology of these materials are characterized by various spectroscopic and diffraction techniques, including Mössbauer spectroscopy, powder X-ray diffraction, Raman and scanning electron microscopy, and BET analysis. Pyrrhotite is found to be the dominant ironcontaining phase. The adsorption performance of microspheres for mercury ion removal from water is studied as a function of adsorbent load and contact time at $\mathrm{pH} 6.5$ using a solution of $40 \mathrm{mg} \mathrm{dm}^{-3}$ mercury ion. Pyrrhotite nanoparticles played a key role in mercury ion removal amounting to $70-90 \%$ of the extracted amount. A high adsorption capacity of $104 \mathrm{mg}$ of mercury/g of adsorbent at an adsorbent load of $0.33 \mathrm{~g} \mathrm{dm}^{-3}$ is achieved, and the removal kinetics could be well fitted with a pseudo-second-order kinetic model, indicating chemical sorption. The synthetic method is easy to scale up for large-scale production and materials are easy to handle, which is significant for large-scale environmental applications.
\end{abstract}

Address correspondence to E-mail: tibor.pasinszki@fnu.ac.fj; tpasinszki@caesar.elte.hu 


\section{Introduction}

Heavy metal contamination in natural waters, soil, and air is one of the major global concerns because of health hazards. Heavy metal ions are not biodegradable and accumulate in the food chain $[1,2]$. Mercury is recognized as one of the most harmful pollutants due to its high toxicity to the central nervous system, kidneys, lung tissues, and reproductive system, as well as high mobility and bioaccumulation [2-5]. Mercury is released into nature by naturogenic and mainly anthropogenic activities, such as geothermal eruptions, seismic activities, fossil fuel combustion, mining, processing of ores, or direct use of mercury in the chemical industry [6-8]. The annual release is estimated to be 8000 tonnes/ year [8]. Due to its toxicity, the maximum permissible level of total mercury in drinking water is 0.002 , 0.0005 , and $0.001 \mathrm{mg} \mathrm{dm}^{-3}$ according to the US Environmental Protection Agency (EPA), Ministry of the Environment of Japan (MEJ), and World Health Organization (WHO) $[9,10]$, respectively. The permitted EPA and MEJ discharge limits for wastewater are 0.010 and $0.005 \mathrm{mg} \mathrm{dm}^{-3}$ [10], respectively. Removing mercury from drinking water and wastewater is therefore of crucial importance. Numerous physical and chemical methods have been developed for this purpose to date based on adsorption, precipitation, coagulation, cementation, solvent extraction, reverse osmosis, photoreduction, ion exchange, membrane separation, electrochemical deposition, or a combination of these methods [3, 6, 10-12]. Among all of these techniques, adsorption is the most commonly used method due to its operational simplicity, removal efficiency, high adsorption rate, and the availability of a wide range of adsorbent materials [12, 13]. Carbonaceous materials are the most widely used adsorbents to date because carbon can be obtained by carbonizing a wide range of natural and synthetic organic precursors. Materials obtained by carbonization are usually post-treated by physical or chemical methods for increasing specific surface area and/or functionalizing. Post-treatments improve adsorption performance and, however, increase the cost of adsorbent production. Although large pore volume and large specific surface area, in general, are expected to increase adsorption capacity, this misconception has been criticized and the synergistic effect of medium to high surface area and well-functionalized surface has been demonstrated for enhancing the mercury removal [6]. It has been widely confirmed that sulfurization of adsorbents results in enhanced adsorption capacity and selectivity toward mercury [6]. The aim of the present work was to develop a low-cost mercury adsorbent that is easy to handle, and the process is easy to scale up. Considering that simple filtration techniques require the particle size to be in the micrometer domain or larger, the aim was to synthesize surface-modified carbon microspheres. All post-treatments have been rejected in this work for cost efficiency; therefore, surface functionalization and carbon matrix generation have been designed to occur simultaneously in one step. Since we have observed recently that appropriately cross-linked polystyrene-based ion exchange resins retain their spherical shape during carbonization [14, 15], an iminodiacetate-functionalized resin was used as the carbon source in our current work. Saturating this resin with a trivalent metal cation requires the presence of a counteranion in the matrix for charge balance; therefore, we expected that saturation with iron(III) sulfate would provide both the sulfur and iron sources for iron sulfide nanoparticle (NP) formation both in the body and more importantly on the surface of carbon microspheres.

In this paper, we present a novel method for producing iron sulfide NP-modified carbon microspheres, the determination of their phase composition and surface morphology, and the study of their performance in mercury removal from water.

\section{Experimental}

\section{Materials and synthesis of carbon microspheres}

All starting materials and chemicals used in this work were reagent grade from commercial sources and used without further purification. A VARION BIM-7 styrene-based cation exchange resin containing $7 \%$ divinylbenzene cross-linker, $2 \%$ acrylonitrile modifier, and iminodiacetate $\left(-\mathrm{N}\left(\mathrm{CH}_{2} \mathrm{COOH}\right)_{2}\right)$ functional groups was used as the starting material. This resin had a nominal binding capacity of $1 \mathrm{~mol}$ divalent metal cation per $1 \mathrm{dm}^{3}$ resin. The resin was saturated with aqueous $\mathrm{Fe}_{2}\left(\mathrm{SO}_{4}\right)_{3}$ solution according to the method described in our previous work [14]. 
Briefly, the resin was conditioned with $1 \mathrm{M}$ aqueous $\mathrm{NaOH}$ solution, washed with distilled water, saturated with threefold excess of $0.5 \mathrm{M}$ aqueous $\mathrm{Fe}_{2}(-$ $\left.\mathrm{SO}_{4}\right)_{3}$ solution, and finally washed with water. The exchanged resin was dried in air for several days and then in a drying box at $120{ }^{\circ} \mathrm{C}$ for 1 day.

The loaded resin, 2-3 grams placed into a porcelain combustion boat, was carbonized in a very slow, high-purity nitrogen stream in a horizontally aligned quartz tube using a tube furnace (see also Refs. $[14,15]$ for more details). The furnace was heated up to the desired temperature in $30 \mathrm{~min}$, kept at this temperature for $4 \mathrm{~h}$, and then left to cool down naturally.

\section{Characterization of NP-modified carbon microspheres}

Mössbauer spectroscopic (MoS) measurements were taken at room temperature using a KFKI Mössbauer spectrometer in constant acceleration mode with a ${ }^{57} \mathrm{Co}(\mathrm{Rh})$ source of $1.5 \mathrm{GBq}$ activity. Spectra were analyzed assuming Lorentzian line shapes using the MossWinn 3.0i XP software, and isomer shifts were determined relative to $\alpha$-Fe reference.

Powder X-ray diffraction (PXRD) measurements were taken on a Model PW 3710/PW 1050 BraggBrentano diffractometer using $\mathrm{Cu} \mathrm{K} \alpha$ radiation $(\lambda=1.541862 \AA)$, secondary beam graphite monochromator, and proportional counter. Lattice parameters were determined using the FullProf Rietveld software suite and the Le Bail whole pattern decomposition method. Silicon powder (NIST SRM 640) and synthetic fluorophlogopite mica (NIST SRM 675) were used as internal two theta standards.

Thermogravimetric (TG)/Mass (MS) measurements were taken on a modified PerkinElmer TGS-2 thermo balance and a HIDEN HAL 2/301 PIC quadrupole mass spectrometer. The dried resin, typically $2.5 \mathrm{mg}$ placed into a platinum sample pan, was heated at a heating rate of $20^{\circ} \mathrm{C} \mathrm{min}{ }^{-1}$ up to $900{ }^{\circ} \mathrm{C}$ in an argon atmosphere. Portions of the volatile products were introduced into the mass spectrometer operated at a $70 \mathrm{eV}$ electron energy through a glass-lined metal capillary transfer line heated to $300{ }^{\circ} \mathrm{C}$.

Scanning electron microscopy (SEM) and energydispersive X-ray analysis (EDX) were performed using an FEI Quanta 3D high-resolution microscope. Resolution of the instrument at $30 \mathrm{keV}$ accelerating voltage and in high vacuum was $\leq 1.2 \mathrm{~nm}$ and $\leq 2.5 \mathrm{~nm}$ using the secondary electron detector (SED) and backscattered electron detector (BSED), respectively. The energy resolution of the $\mathrm{X}$-ray detector (EDX) was $130 \mathrm{eV}$ at $\mathrm{Mn} \mathrm{K \alpha}$.

Raman spectra were recorded on a confocal Horiba Jobin Yvon LabRAM HR Raman microscope using $\mathrm{He}-\mathrm{Ne}$ excitation $(632 \mathrm{~nm})$ and a laser power of 0.1 $\mathrm{mW}$.

BET specific surface area (SSA) of carbon microspheres was determined using an ASDI RXM-100 Catalyst Characterization instrument, nitrogen gas at liquid nitrogen temperature, and the volumetric method. Nitrogen sorption experiments were done using a Quantachrome Autosorb 1C static volumetric apparatus at $77 \mathrm{~K}$ by measuring the increase in volume at equilibrium as a function of the relative pressure. Adsorption data were obtained applying successive doses of the selected gas until $p / p_{0}=1$ relative pressure was reached. Microspheres were outgassed prior to measurements at $300{ }^{\circ} \mathrm{C}$ for $24 \mathrm{~h}$.

Iron ion concentrations in aqueous samples were determined using a Spectro Genesis ICP-OES simultaneous spectrometer with axial plasma observation. The mercury ion determination in aqueous samples, however, was not possible using this ICP-OES due to unrealistic results. Therefore, mercury ion concentrations in aqueous samples were determined using the spectrophotometric method based on the absorbance of the $\mathrm{Hg}$-thiocyanate-rhodamine $\mathrm{B}$ (RB) complex $\mathrm{Hg}^{2+}\left(\mathrm{SCN}^{-}\right)_{4}\left(\mathrm{RB}^{+}\right)_{2}$ as described in the literature [16]. Measurements were taken using a PerkinElmer UV/Vis Lambda 35 spectrometer applying a slit width of $1 \mathrm{~nm}$.

\section{Batch adsorption of $\mathrm{Hg}$ (II)}

The adsorption performance of microspheres was determined using stock $\mathrm{Hg}\left(\mathrm{NO}_{3}\right)_{2}$ solutions with known $\mathrm{Hg}^{2+}$ concentration of 10,20 and $40 \mathrm{mg} \mathrm{dm}^{-3}$. Typically, $30 \mathrm{ml}$ of stock solution was treated with 10,25 , or $50 \mathrm{mg}$ adsorbent at $25 \pm 1{ }^{\circ} \mathrm{C}$ at $\mathrm{pH} 6.5$ for one day. The $\mathrm{Hg}^{2+}$ concentration before and after the treatment was determined using UVVis spectroscopy by measuring the absorbance of $\mathrm{Hg}$-thiocyanate-RB complex at $610 \mathrm{~nm}$. The amount of $\mathrm{Hg}^{2+}$ adsorbed on microspheres $\left(q_{t}, \mathrm{mg} \mathrm{g}^{-1}\right)$ was calculated using Eq. (1) 
$q_{t}=\frac{\left(A_{0}-A_{t}\right)}{A_{0}} \cdot \frac{c_{0} \cdot V}{m}$

where $A_{0}$ and $A_{t}$ are the initial absorbance and absorbance at time $t, c_{0}$ is the initial $\mathrm{Hg}^{2+}$ concentration $\left(\mathrm{mg} \mathrm{dm}^{-3}\right), V$ is the volume of the solution $\left(\mathrm{dm}^{3}\right)$, and $m$ is the mass of adsorbent $(\mathrm{g})$.

Kinetic measurements were taken at $25 \pm 1{ }^{\circ} \mathrm{C}$ and at $\mathrm{pH}$ 6.5. The pseudo-second-order rate equation [17] was expressed as follows (2)

$\frac{t}{q_{t}}=\frac{1}{k_{\mathrm{ad}} \cdot q_{\mathrm{eq}}^{2}}+\frac{t}{q_{\mathrm{eq}}}$

where $t=$ time, $q_{\mathrm{eq}}=$ adsorbed amount of $\mathrm{Hg}^{2+}$ at equilibrium $\left(\mathrm{mg} \mathrm{g}^{-1}\right), q_{t}=$ adsorbed amount of $\mathrm{Hg}^{2+}$ at time $t\left(\mathrm{mg} \mathrm{g}^{-1}\right)$, and $k_{\mathrm{ad}}=$ adsorption rate constant.

For determining the adsorbed amount of mercury, three replicate syntheses and analyses were carried out and the average value is reported with uncertainty values of $\pm 4 \mathrm{mg} \mathrm{g}^{-1}$.

\section{Results and discussion}

\section{Resin loading and carbonization experiments}

Our aim was to synthesize iron sulfide NP-modified carbon microspheres; therefore, critical questions were whether the sulfate ion stays in the resin as a counterion after cation exchange and whether iron sulfide NPs form during carbonization. The Fe-to-S ratio of the dried resin was determined on several points of its surface using EDX, and an average ratio of about 1:1 was obtained. (Note that EDX is a semiquantitative method; Fe-to-S ratios varied between 1.06:1 and 0.93:1; an example is shown in Figure S1 in Supporting Material.) The functional groups of the loaded resin can thus be described as [$\left.\mathrm{NH}^{+}\left(\mathrm{CH}_{2} \mathrm{COO}^{-}\right)_{2} \mathrm{Fe}^{3+}\left(\mathrm{H}_{2} \mathrm{O}\right)_{x}\right] \mathrm{SO}_{4}{ }^{2-}$. The iron content on the surface of loaded resins was measured to be $7.2 \%$ by EDX. To find the right carbonization temperature, the thermal stability of iron sulfateloaded resin was studied by TG-MS. The weight loss of the resin started steadily about $187^{\circ} \mathrm{C}$, and the main decomposition occurred at about $432{ }^{\circ} \mathrm{C}$ (see Fig. 1). The weight loss up to $900{ }^{\circ} \mathrm{C}$ was $69.4 \%$. MS monitoring of the decomposition identified $\mathrm{CO}_{2}$ and $\mathrm{H}_{2} \mathrm{O}$ as major decomposition products at lower temperatures what indicated decarboxylation of the

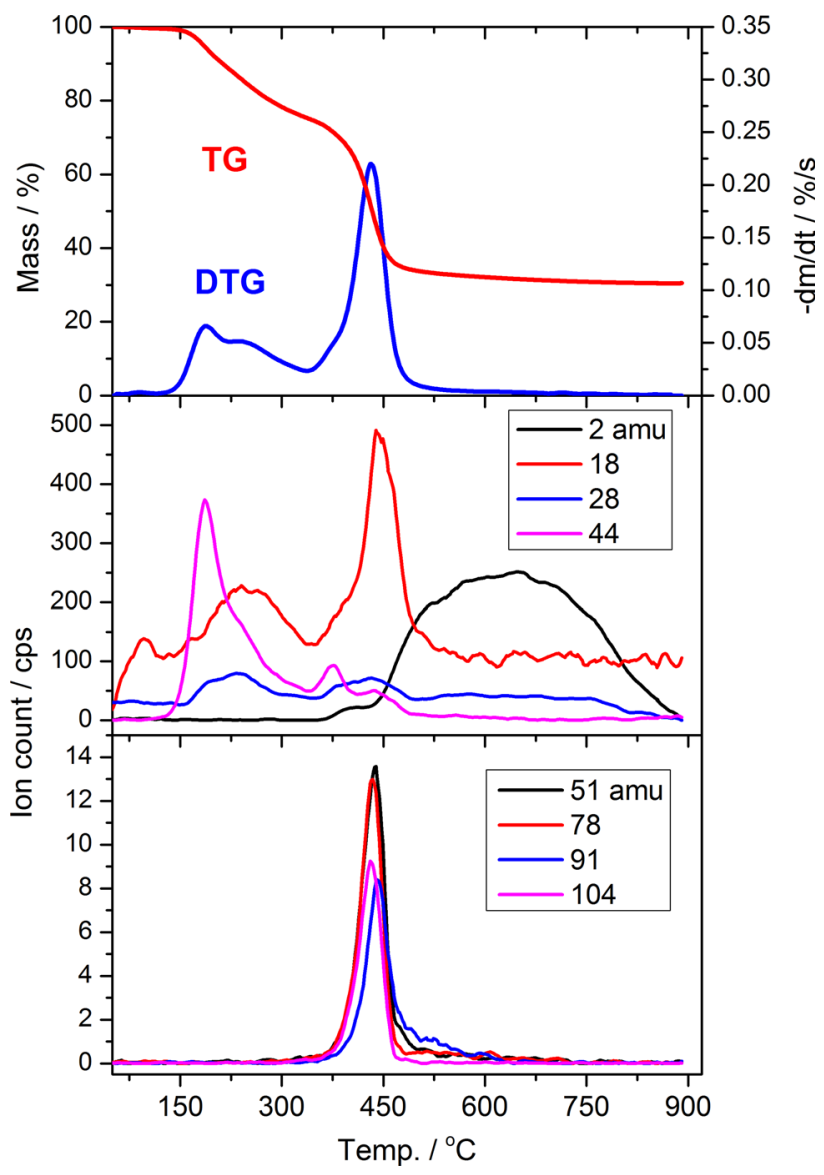

Figure 1 Top: TG curves of iron(III) sulfate-loaded resin (heating rate $20{ }^{\circ} \mathrm{C} \mathrm{min}{ }^{-1}$, Ar atmosphere), middle and bottom: ion count curves in MS (mass in amu is indicated in figure).

resin and partial loss of coordinated water (Fig. 1). The polymer backbone decomposition and hydrocarbon (e.g., benzene and styrene) formation occurred in the main decomposition step (Fig. 1). Hydrogen formation was detected at high temperatures above $500{ }^{\circ} \mathrm{C}$, possibly due to water-carbon reaction. It has to be noted that the sensitivity of the mass analyzer is gradually decreasing with increasing mass; therefore, the relative ion currents do not represent their relative amounts. The weight loss of carbonized resin was small above $500{ }^{\circ} \mathrm{C}$; therefore, the carbonization of the resin on a larger scale using a furnace was investigated in the $500-1000{ }^{\circ} \mathrm{C}$ temperature range in $100{ }^{\circ} \mathrm{C}$ increments.

\section{Phase analysis}

The phase compositions of carbon microspheres prepared by carbonization at various temperatures were determined using MoS (Figs. 2 and S2-S7), 


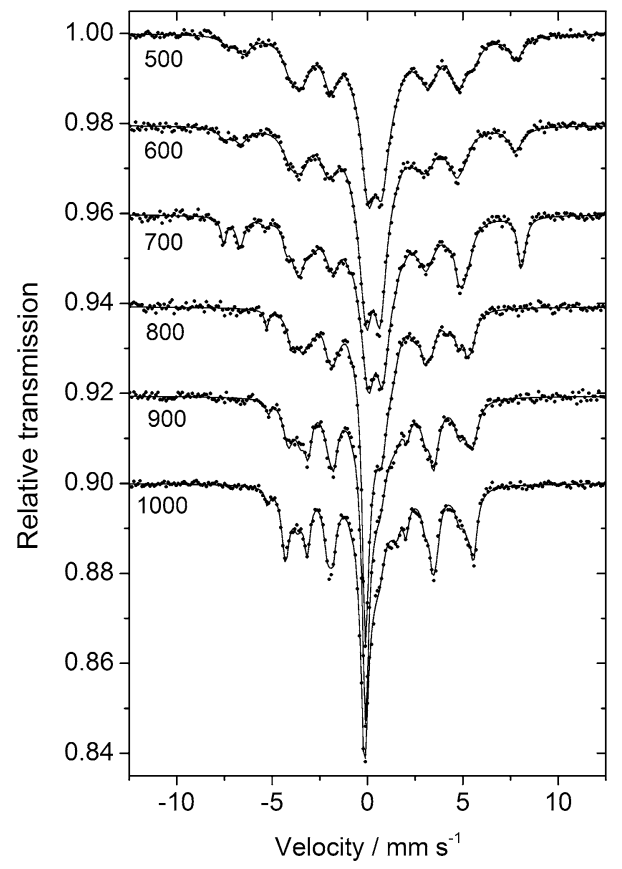

Figure 2 Mössbauer spectra of synthesized microspheres (carbonization temperature in ${ }^{\circ} \mathrm{C}$ is indicated in figure; spectra are shifted for clarity; see detailed decomposition of spectra in supplementary material, Figures S2-S7).

PXRD (Figures S8-S13), and Raman microscopy (see below). Non-stoichiometric iron monosulfide (FeS) was identified as the major iron compound. Magnetite $\left(\mathrm{Fe}_{3} \mathrm{O}_{4}\right)$ appeared as a minor component at lower temperatures between 500 and $700{ }^{\circ} \mathrm{C}$, and it was replaced by elemental iron (both $\alpha$ and $\gamma$ ) and cementite $\left(\mathrm{Fe}_{3} \mathrm{C}\right)$ at higher temperatures (see Table 1).
At least two or more phases of non-stoichiometric and stoichiometric iron monosulfide ( $\mathrm{FeS}$ ) formed during thermal decomposition of the resin. It was not possible, however, to distinguish between these FeS phases due to their similarity. PXRD patterns of various pyrrhotite $\mathrm{Fe}_{1-x} \mathrm{~S}(x=0.875-0.92)$ and troilite FeS phases are very similar, particularly for nonzero $x$ [18]. We note that neither troilite nor any pyrrhotite single phase could perfectly describe the experimental PXRD patterns, although any of them provided a reasonable fit. Two hexagonal pyrrhotite phases were therefore used to describe PXRD patterns for microspheres obtained at 500, 600, and $700{ }^{\circ} \mathrm{C}$, and only one for samples obtained at 800,900 , and $1000{ }^{\circ} \mathrm{C}$. The average pyrrhotite crystallite size is observed to increase slightly by increasing the carbonization temperature and estimated to be around $20 \mathrm{~nm}$ at $500{ }^{\circ} \mathrm{C}$ and $25 \mathrm{~nm}$ at $1000{ }^{\circ} \mathrm{C}$ (Table S2). Graphitization was not observed by PXRD. MoS spectra were very complicated due to the large number of overlapping sextets making the fit for FeS phases ambiguous. MoS spectra could be described by fitting an additional superparamagnetic pyrrhotite component (Table 1, Fig. 2). The latter together with the normal component indicated a wide crystallite size distribution.

Raman microscopy confirmed the carbonization of the resin. Raman spectra recorded on several spots of microspheres exhibited two strong bands, a broader and stronger at 1331-1351 and a narrower with smaller intensity at $1591-1597 \mathrm{~cm}^{-1}$, assigned to
Table 1 Iron-containing phase composition of

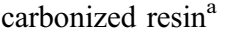

\begin{tabular}{|c|c|c|c|c|c|c|c|c|c|c|}
\hline \multirow{2}{*}{$\begin{array}{r}\text { Carb. } \\
{ }^{\circ} \mathrm{C}\end{array}$} & \multicolumn{2}{|l|}{$\alpha-\mathrm{Fe}$} & \multicolumn{2}{|l|}{$\gamma-\mathrm{Fe}$} & \multicolumn{2}{|l|}{$\mathrm{Fe}_{3} \mathrm{C}$} & \multicolumn{2}{|c|}{$\mathrm{Fe}_{1-x} \mathrm{~S}$} & \multicolumn{2}{|l|}{$\mathrm{Fe}_{3} \mathrm{O}_{4}$} \\
\hline & XRD & MoS & XRD & MoS & XRD & MoS & XRD & $\mathrm{MoS}^{\mathrm{c}}$ & XRD & $\mathrm{MoS}$ \\
\hline 500 & & & & & & & $77^{d}$ & 83 (39) & 23 & 17 \\
\hline 600 & & & & & & & $83^{\mathrm{d}}$ & $84(47)$ & 17 & 16 \\
\hline 700 & 3 & 2 & & & & & $77^{\mathrm{d}}$ & 80 (39) & 20 & 18 \\
\hline 800 & 5 & 4 & 10 & 16 & & & 85 & $80(38)$ & & \\
\hline 900 & 5 & 4 & 17 & 19 & & & 78 & $77(25)$ & & \\
\hline 1000 & 7 & 4 & 21 & 17 & 10 & 14 & 63 & $65(22)$ & & \\
\hline
\end{tabular}

${ }^{\mathrm{a}} \mathrm{Fe}$ content in at.\%. Notation: MoS, Mössbauer spectroscopy; XRD, powder X-ray diffraction; estimated errors for MoS and XRD are within $\pm 1 \%$ and $\pm 5 \%$, respectively

${ }^{\mathrm{b}}$ Carbonized for $4 \mathrm{~h}$

${ }^{\mathrm{c}}$ Amount of superparamagnetic component is shown in parenthesis

${ }^{\mathrm{d}}$ Two non-stoichiometric hexagonal pyrrhotite phases were detected: pyrrhotite 1: $a_{0}=6.867 \AA$, $c_{0}=17.072 \AA$, pyrrhotite $2: a_{0}=6.80 \AA, c_{0}=16.44 \AA$ 


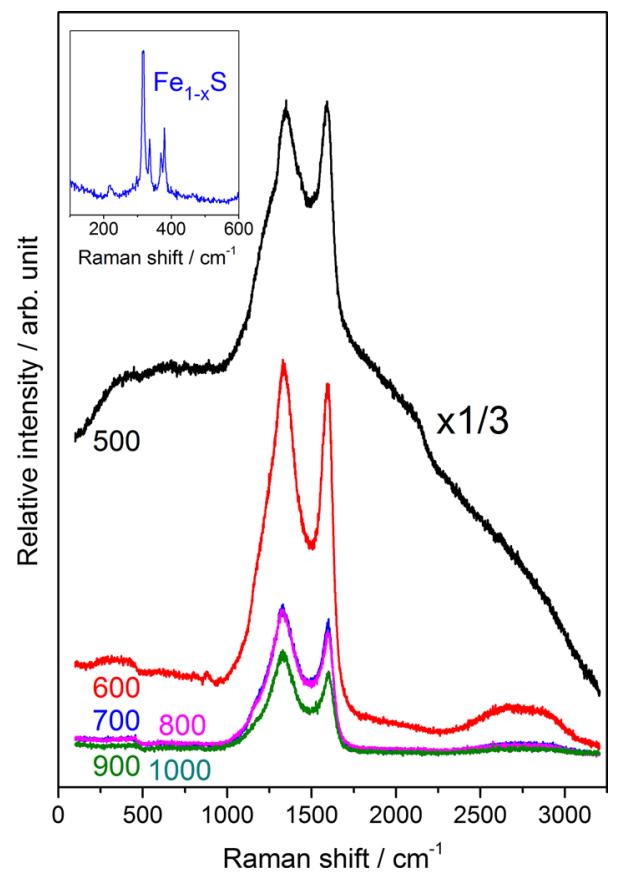

Figure 3 Typical Raman spectra of microspheres at different carbonization temperatures $\left({ }^{\circ} \mathrm{C}\right)$. Inset, top, shows Raman bands of pyrrhotite detected on the surface of microspheres prepared by carbonization at $900{ }^{\circ} \mathrm{C}$.

carbonic D and G bands, respectively (Fig. 3). The D band is associated with the vibrational mode of $s p^{3}$ bonded carbon atoms, while the $G$ band is related to graphitic $s p^{2}$ carbon structures. The $\mathrm{D}$ band exhibited a shoulder at around $1155-1173 \mathrm{~cm}^{-1}$ which may arise due to $s p^{2}-s p^{3}$ bonds or polyene-like structures [19]. Weak second-order Raman bands are also detected in the $2500-3000 \mathrm{~cm}^{-1}$ region. The appearance of these first- and second-order Raman bands, as well as the D/G band intensity ratio, is characteristic of amorphous carbon [14]. Raman measurements indicate a low degree of graphitization for synthesized microspheres, in agreement with PXRD. The detected Raman bands appear on top of a broad luminescence background at $500{ }^{\circ} \mathrm{C}$ carbonization, which indicates imperfect carbonization at this temperature, but this background disappears with increasing carbonization temperature. The measured Raman intensity, in general, decreases with increasing carbonization temperature, which indicates gradual replacement of $s p^{3}$ carbon atoms by $s p^{2}$ carbon atoms. Since the laser spot of our Raman microscope was about $500 \mathrm{~nm}$, larger crystallites on the surface of microspheres could be detected. Mapping microspheres' surfaces, Raman bands characteristic of pyrrhotite [20, 21] were identified at 316, 336, 369, and $379 \mathrm{~cm}^{-1}$ (see Fig. 3, inset). Immersing microspheres into $18 \%$ aqueous hydrochloric acid, the characteristic smell of $\mathrm{H}_{2} \mathrm{~S}$ could be instantly observed, what provided further support for the
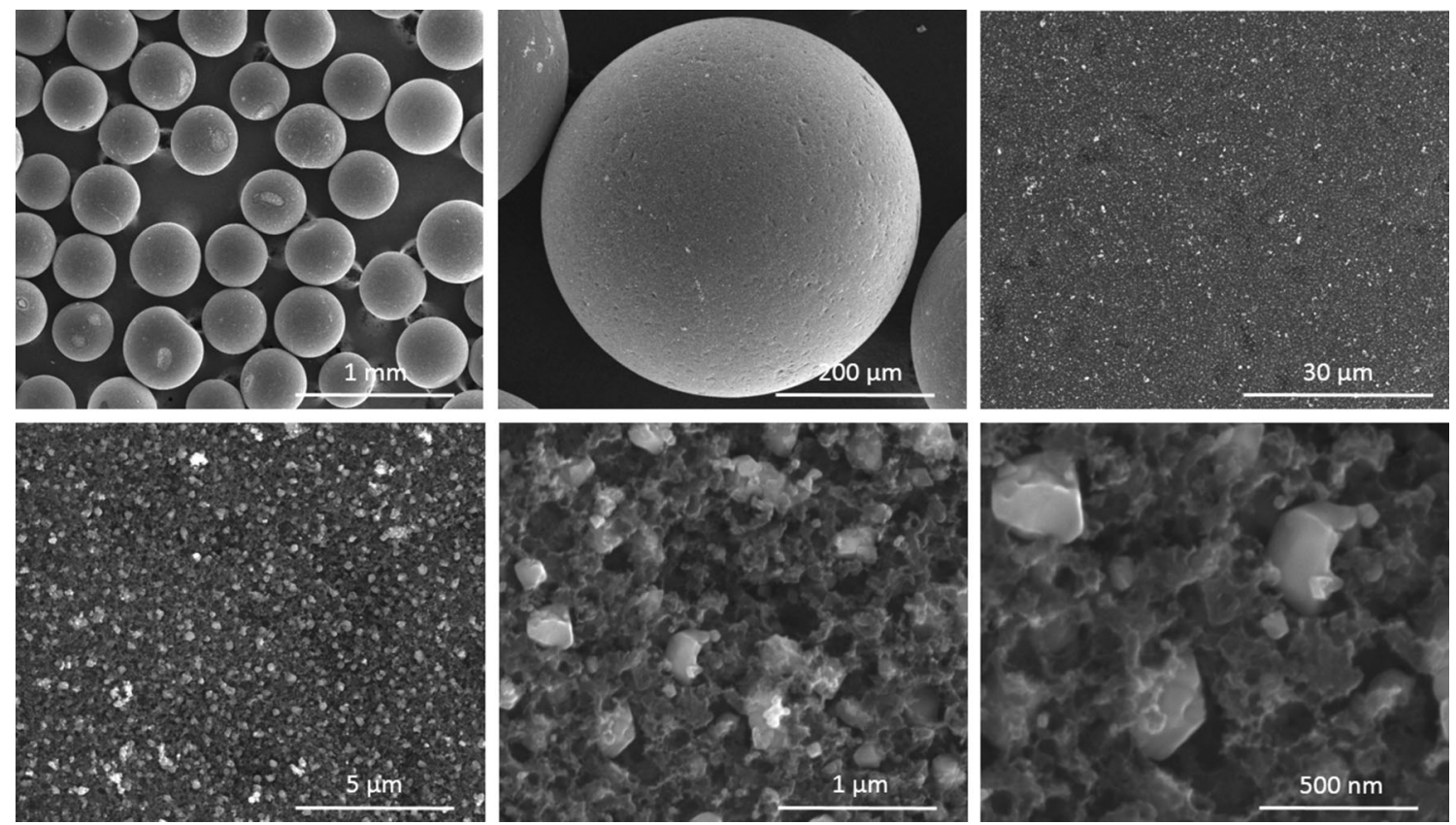

Figure 4 SEM images of microspheres prepared by carbonization at $900{ }^{\circ} \mathrm{C}$ (see Figures S14-S19 for images of microspheres prepared at other temperatures).

\section{Springer}


formation of pyrrhotite crystals on the microspheres' surfaces.

\section{Surface morphology and specific surface area}

According to SEM investigation, the synthesized microspheres inherited the spherical morphology of ion exchange resins (original diameter between 600 and $900 \mu \mathrm{m}$ ), but shrunk during the heat treatment to 300-500 $\mu \mathrm{m}$ (Figs. 4 and S14-S19). Macropores and small crystallites were well observable on the surface of microspheres. The size of crystallites gradually increased and crystallites became more exposed on the surface by increasing carbonization temperature. Relatively large crystallites even with a diameter up to $250 \mathrm{~nm}$ were also obtained (Fig. 4), and possibly these were detected with Raman spectroscopy (see above). These crystallites could be removed from the surface by $18 \%$ aqueous hydrochloric acid treatment (see Figure S20). Iron ions were leaching out from the surface into the solution, and their concentration was determined by ICP-OES analysis to be between 5.1 and $6.3 \%$. Although surface iron leachable by acid gradually increased by increasing the carbonization temperature, differences were surprisingly small between microspheres prepared at different temperatures. It is worth noting that acid treatment is very effective to remove all iron-containing phases where the crystallite is not perfectly surrounded by the inert carbon matrix.

The BET specific surface areas of microspheres were determined using nitrogen adsorption measurements, and results are shown in Fig. 5 and listed in Table S3. The SSA of microspheres obtained by carbonizing at $500{ }^{\circ} \mathrm{C}$ was $278 \mathrm{~m}^{2} \mathrm{~g}^{-1}$, and the SSA gradually decreased to $72 \mathrm{~m}^{2} \mathrm{~g}^{-1}$ at $1000{ }^{\circ} \mathrm{C}$ with increasing temperature, possibly due to sintering the surface. SSA decreased by about $30 \%$ by removing NPs from surfaces using hydrochloric acid (see Table S3). Nitrogen adsorption-desorption isotherm was measured for microspheres prepared at $900{ }^{\circ} \mathrm{C}$ because they exhibited the best performance for mercury removal (see below). The isotherm (Fig. 5) and pore volume distribution (Figure S21) indicated poorly developed micro- and mesopores. (The calculated total pore volume for micro- and mesopores was only 0.022 and $0.17 \mathrm{~cm}^{3} \mathrm{~g}^{-1}$ at $p / p_{0}=0.97939$; no special pore width was obtained.) According to IUPAC classification, the isotherm is a type IV with
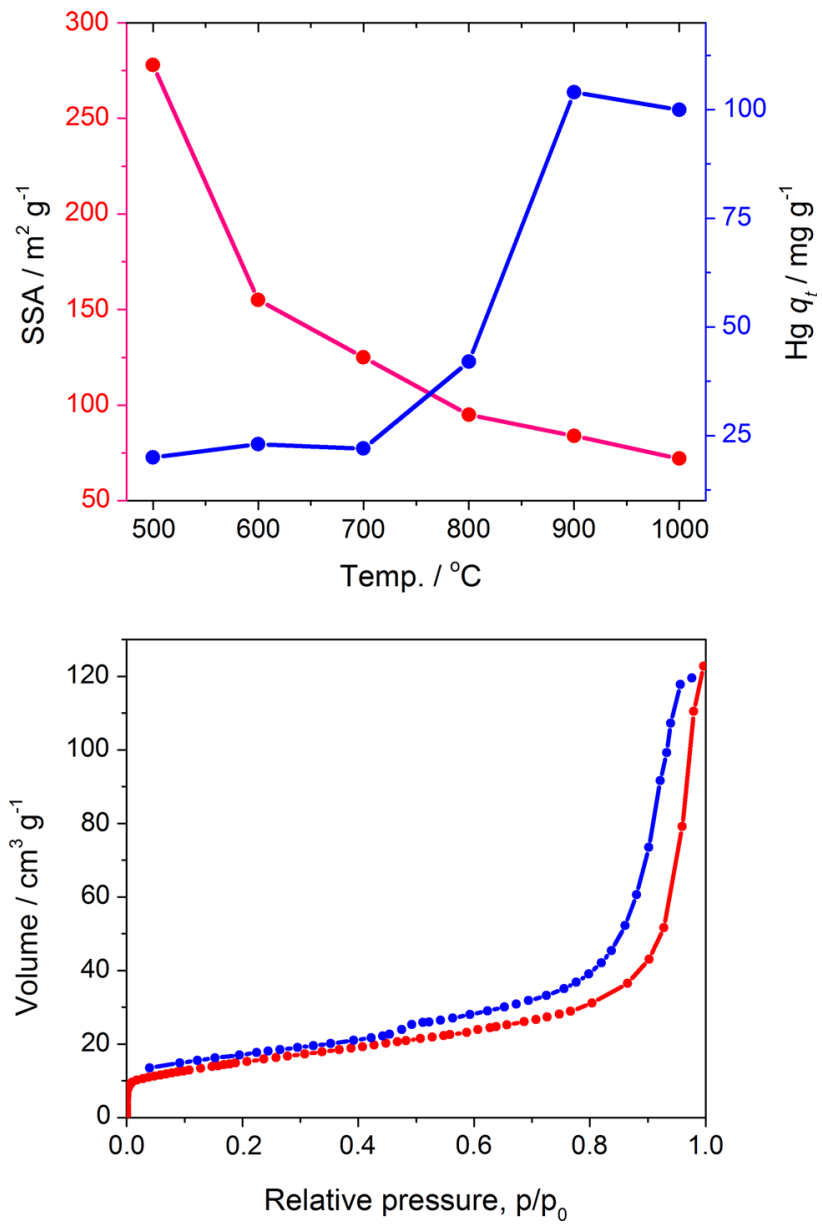

Figure 5 Top: Relationship between carbonization temperature and specific surface area (SSA) and mercury adsorption capacity $\left(q_{t}\right)$ of carbon microspheres. Bottom: $\mathrm{N}_{2}$ adsorption-desorption isotherms of microspheres prepared at $900{ }^{\circ} \mathrm{C}$ (type IV, H3).

an H3 hysteresis loop, characteristic of non-rigid aggregates of particles on the surface or not completely filled macropores of the pore network [22].

\section{Mercury removal from water}

The mercury removal capacity and efficiency of synthesized microspheres were studied by treating $30 \mathrm{ml}$ aqueous $\mathrm{Hg}\left(\mathrm{NO}_{3}\right)_{2}$ solution with a $\mathrm{Hg}^{2+}$ concentration of 10,20 , or $40 \mathrm{mg} \mathrm{dm}^{-3}$ at $\mathrm{pH} 6.5$ for one day using 10, 25, or $50 \mathrm{mg}$ adsorbent load. The $\mathrm{Hg}^{2+}$ concentration before and after the treatment was determined by UV-Vis spectroscopy. Hundred percentage mercury removal efficiency was obtained for solutions with 10 or $20 \mathrm{mg} \mathrm{dm}{ }^{-3} \mathrm{Hg}^{2+}$ even at $10 \mathrm{mg}$ adsorbent load for the best performers; therefore, the solution with $\mathrm{Hg}^{2+}$ concentration of $40 \mathrm{mg} \mathrm{dm}^{-3}$ was used as the case study. Adsorption capacities were 


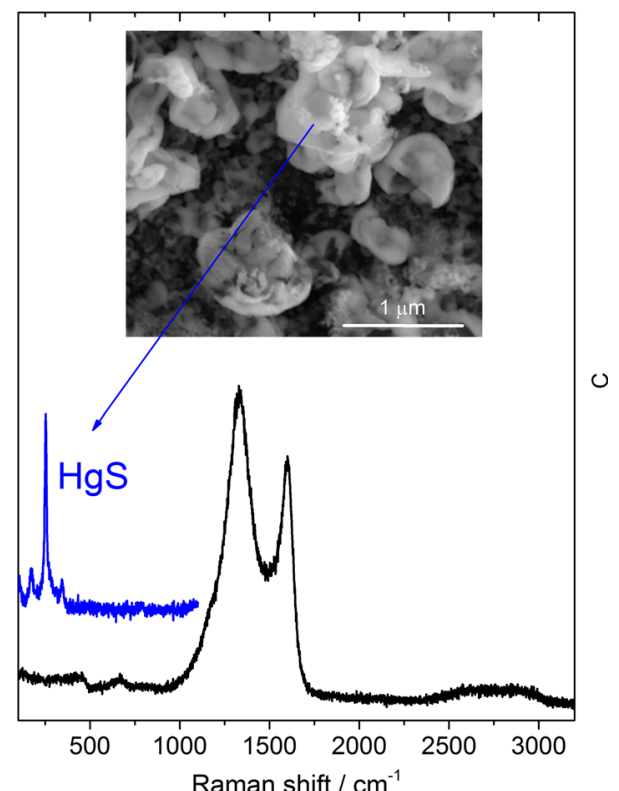

Figure 6 Bottom: typical Raman spectrum of carbon microspheres prepared by carbonization at $900{ }^{\circ} \mathrm{C}$; inset shows Raman spectrum of deposited $\mathrm{HgS}$ on these microsphere surfaces after treatment with aqueous solution of mercury ions. Top: SEM image of a microsphere surface after mercury ion sorption (see also Figure S22).

obtained to be relatively small for microspheres prepared at lower temperatures, but they strongly increased by increasing carbonization temperatures. They were 20, 23, 22, 42, 104, and $100 \pm 4 \mathrm{mg} \mathrm{g}^{-1}$ for microspheres carbonized at 500, 600, 700, 800, 900, and $1000{ }^{\circ} \mathrm{C}$, respectively. This trend is just the opposite of that of SSA (Fig. 5), which indicates that not the SSA is the determining factor in mercury removal. Investigating microspheres after mercury adsorption by SEM, deposits of new crystallites were detected (Figs. 6 and S22). EDX indicated a 1:1 Hg-to$S$ ratio in the deposited material (Figure S23) and Raman microscopy unambiguously identified $\mathrm{HgS}$ [23]. (Strong and weak characteristic bands of $\mathrm{HgS}$ are observed at 253 and $344 \mathrm{~cm}^{-1}$, respectively; see Fig. 6.) During the adsorption of mercury ions, iron was leaching out of the surface into the solution, and it was measured by ICP-OES to be 4, 5, 5, 10, 27, and $27 \mathrm{mg} \mathrm{g}^{-1}$ for microspheres obtained at 500, 600, 700, 800,900 , and $1000{ }^{\circ} \mathrm{C}$, respectively. The mechanism of $\mathrm{Hg}^{2+}$ removal by iron sulfide nanoparticles is generally described by three processes, namely adsorption, ion exchange, and precipitation [24-27]. The latter two result in iron leaching into the solution. In addition, it cannot be ruled out that small amounts
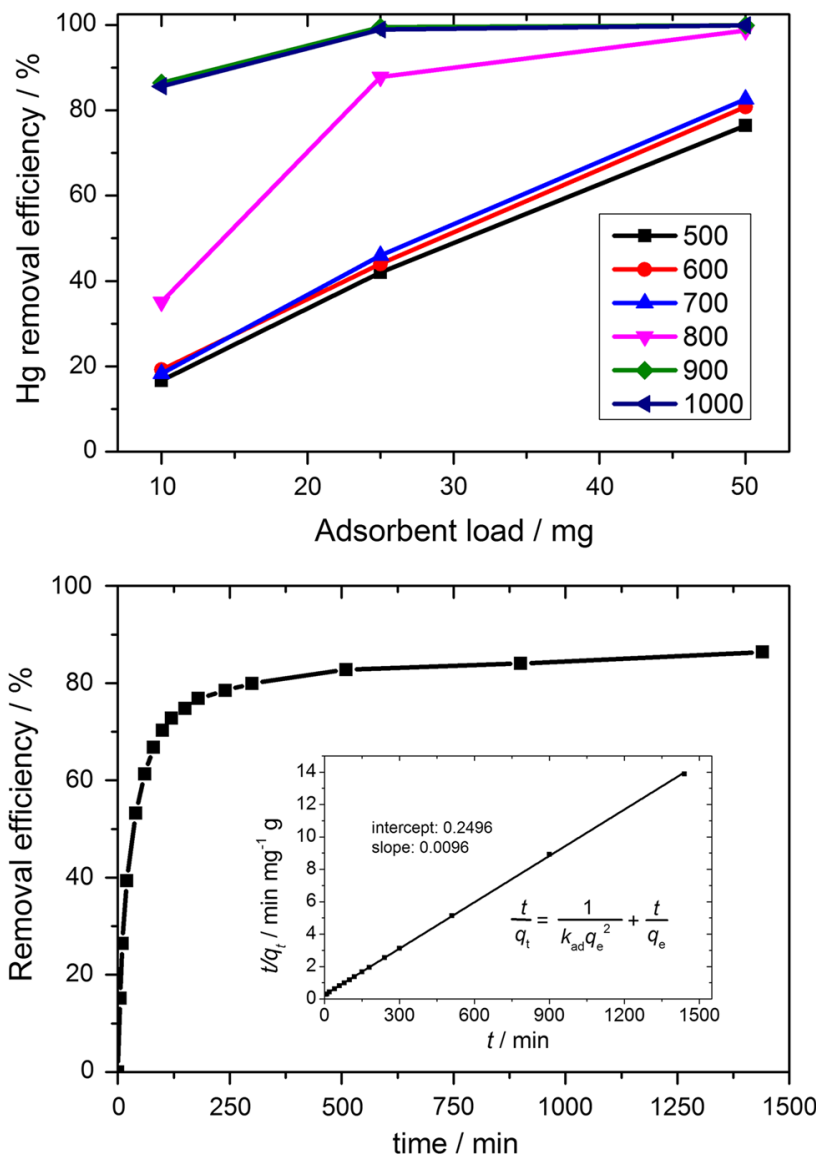

Figure 7 Top: $\mathrm{Hg}$ removal efficiency $\left(30 \mathrm{ml} 40 \mathrm{mg} \mathrm{dm}^{-3}\right.$ aq. $\mathrm{Hg}^{2+}$ solution was treated with 10,25 or $50 \mathrm{mg}$ adsorbent for 1 day; carbonization temperature in ${ }^{\circ} \mathrm{C}$ is indicated in figure). Bottom: Kinetics of $\mathrm{Hg}^{2+}$ removal from aqueous solution using an initial $\mathrm{Hg}^{2+}$ concentration of $40 \mathrm{mg} \mathrm{dm}^{-3}$ and adsorbent load of $0.33 \mathrm{~g} \mathrm{dm}^{-3}$; insert shows fitting of pseudo-second-order kinetics.

of iron NPs exist on the microsphere surfaces (see Table 1 for phase composition). A clear correlation is observed between the mercury ion removal from solution and iron dissolution in our experiments, namely larger adsorption capacity associated with larger iron dissolution. The amount of $\mathrm{Hg}^{2+}$ ions removed from the solution by chemical reactions can be estimated by assuming a 1:1 replacement of iron by mercury $\left(\mathrm{FeS}+\mathrm{Hg}^{2+} \rightarrow \mathrm{HgS}+\mathrm{Fe}^{2+}, \mathrm{FeS}+\right.$ $\mathrm{xHg}^{2+} \rightarrow \mathrm{Fe}_{1-\mathrm{x}} \mathrm{Hg}_{\mathrm{x}} \mathrm{S}+\mathrm{xFe}^{2+}$, and $\mathrm{Fe}+\mathrm{Hg}^{2+}$ $\rightarrow \mathrm{Hg}+\mathrm{Fe}^{2+}$ reactions), and calculating the deposited mercury and leached iron from adsorption capacities and ICP-OES data, respectively. According to this, $70-90 \%$ of mercury ions are estimated to be removed from the solution due to chemical reactions and $10-30 \%$ by physisorption, indicating that precipitation and ion exchange are important processes 
Table 2 Comparison of experimental conditions and adsorption capacity of $\mathrm{Hg}^{2+}$ ion adsorbents

\begin{tabular}{|c|c|c|c|c|c|c|}
\hline Adsorbent $\mathrm{a}^{\mathrm{a}}$ & $\begin{array}{l}\text { Initial } \mathrm{Hg}^{2+} \text { conc. } \\
\left(\mathrm{mg} \mathrm{dm}^{-3}\right)\end{array}$ & $\begin{array}{l}\text { Adsorbent load } \\
\left(\mathrm{g} \mathrm{dm}^{-3}\right)\end{array}$ & Temp. $\left({ }^{\circ} \mathrm{C}\right)$ & $\mathrm{pH}$ & $\begin{array}{l}\text { Adsorption capacity } \\
\left(\mathrm{mg} \mathrm{g}^{-1}\right)\end{array}$ & References \\
\hline Sulfur-containing MWCNT & 0.1 & 5 & n.a. & 12 & 0.0728 & {$[28]$} \\
\hline Sulfur-containing AC & 0.1 & 5 & n.a. & 12 & 0.0447 & {$[28]$} \\
\hline Sulfur-impregnated AC & 20 & 5 & 25 & 2 & 4 & [29] \\
\hline Thiolated MWCNT/ $\mathrm{Fe}_{3} \mathrm{O}_{4}$ & 50 & 1 & 25 & 6.5 & 65.52 & {$[30]$} \\
\hline Sulfur-impregnated AC & 100 & 1 & 25 & 5 & 71.5 & {$[31]$} \\
\hline Thiolated MWCNT & $5-100$ & 0.4 & 25 & 6 & 84.66 & {$[32]$} \\
\hline $\mathrm{Fe}_{1-x} \mathrm{~S} \mathrm{NP} / \mathrm{C}$ microspheres & 40 & 0.333 & 25 & 6.5 & $104^{\mathrm{c}}$ & This work \\
\hline Thiol-derivatized SWCNT & $20-40$ & 0.25 & 25 & 5 & 131 & {$[33]$} \\
\hline $\mathrm{CS}_{2}$-treated $\mathrm{AC}$ & $200-2000$ & 1 & 27 & 2 & 357 & {$[34]$} \\
\hline
\end{tabular}

${ }^{a}$ Notations: $A C$ activated carbon, GO graphene oxide, IL ionic liquid, MWCNT multi-walled carbon nanotube, n.a. not available

${ }^{\mathrm{b}}$ Maximum adsorption capacity

${ }^{\mathrm{c}}$ Equilibrium sorption capacity

in the mercury removal mechanism (also note deposited HgS detected by Raman). Microspheres obtained by carbonizing the resin at $900{ }^{\circ} \mathrm{C}$ exhibited the highest sorption capacity of $104 \mathrm{mg} \mathrm{g}^{-1}$. The mercury ion removal efficiency of this material was obtained to be $86.4,99.6$, and $100.0 \%$ using a sorbent load of $0.33,0.83$, and $1.67 \mathrm{mg}$ sorbent per $1 \mathrm{dm}^{3}$ $\mathrm{Hg}^{2+}$ solution, corresponding to $5.44,0.16$, and $0.0 \mathrm{mg} \mathrm{dm}^{-3}$ remaining $\mathrm{Hg}^{2+}$ ion concentration in treated solutions, respectively. The sorption kinetics of this material was studied using a sorbent concentration of $0.33 \mathrm{~g} \mathrm{dm}^{-3}$. Experimental data could be well fitted using a pseudo-second-order kinetic model [17] (see Fig. 7), from which the sorption rate constant was calculated to be $3.69 \times 10^{-4} \mathrm{~g} \mathrm{mg}^{-1}$ $\min ^{-1}$. The initial adsorption rate was obtained to be $4.01 \mathrm{mg} \mathrm{g}^{-1} \mathrm{~min}^{-1}$. $50 \%$ of the adsorbed mercury ions were removed in $13 \mathrm{~min}$. Several carbon-based materials have been synthesized, activated, and tested for mercury removal to date [6, 12]. A comparison of the sorption performance of synthesized microspheres to those of relevant thiolated carbonaceous sorbents published in the literature is shown in Table 2. Microspheres have relatively high adsorption capacity, even without using any activation method. The $\mathrm{Hg}^{2+}$ removal efficiency, namely $100 \%$, as well as the production and application simplicity of the novel microspheres is very advantageous for wide-scale applications compared to previously synthesized materials.

\section{Conclusions}

Carbon microspheres modified with iron sulfide NPs are successfully synthesized in this work and applied for mercury ion removal from water. Microspheres were synthesized by carbonizing a polystyrene-based ion exchange resin loaded with $\mathrm{Fe}_{2}\left(\mathrm{SO}_{4}\right)_{3}$ solution in the temperature range of $500-1000{ }^{\circ} \mathrm{C} . \quad \mathrm{Fe}_{2}\left(\mathrm{SO}_{4}\right)_{3}$ served as the iron and sulfur source, and the resin as the carbon source. Pyrrhotite NPs were identified as the major iron-containing phase formed in the reductive atmosphere of resin decomposition, and they played a key role in mercury ion removal from water by forming mercury sulfide on the surface of microspheres. The prepared materials are effective sorbents for mercury removal from water with an excellent removal efficiency, showing capability to purify contaminated water to reach the drinking water criteria. The synthetic procedure is simple and easy to scale up. The latter and the excellent removal efficiency of synthesized materials are advantageous for large-scale applications.

\section{Acknowledgements}

Open access funding provided by Eötvös Loránd University (ELTE). The authors thank Gábor Varga, Imre Kovács, Szilvia Klébert, Zoltán May, and Zsuzsanna Czégény for their assistance in SEM, BET, ICP-OES, and TG-MS measurements. TP and DC thank the Fiji National University for supporting this research (Grant No. URC027). 


\section{Compliance with ethical standards}

Conflict of interest The authors declare that they have no conflict of interest.

Electronic supplementary material: The online version of this article (https://doi.org/10.1007/s108 53-019-04032-3) contains supplementary material, which is available to authorized users.

Open Access This article is distributed under the terms of the Creative Commons Attribution 4.0 International License (http://creativecommons.org/ licenses/by/4.0/), which permits unrestricted use, distribution, and reproduction in any medium, provided you give appropriate credit to the original author(s) and the source, provide a link to the Creative Commons license, and indicate if changes were made.

Electronic supplementary material: The online version of this article (https://doi.org/10.1007/s108 53-019-04032-3) contains supplementary material, which is available to authorized users.

\section{References}

[1] Raehsler SL, Choung RS, Marietta EV, Murray JA (2018) Accumulation of heavy metals in people on a gluten-free diet. Clin Gastroenterol Hepatol 16:244-251

[2] Jaishankar M, Tseten T, Anbalagan N, Mathew BB, Beeregowda KN (2014) Toxicity, mechanism and health effects of some heavy metals. Interdiscip Toxicol 7:60-72

[3] Tunsu C, Wickman B (2018) Effective removal of mercury from aqueous streams via electrochemical alloy formation on platinum. Nat Comm 9:4876

[4] Habila MA, AlOthman ZA, Ghfar AA, Al-Zaben MIM, Alothman AAS, Abdeltawab AA, El-Marghany A, Sheikh M (2019) Phosphonium-based ionic liquid modified activated carbon from mixed recyclable waste for mercury(II) uptake. Molecules 24:570

[5] Huang S, Ma C, Liao Y, Min C, Du P, Jiang Y (2016) Removal of mercury(II) from aqueous solutions by adsorption on poly(1-amino-5-chloroanthraquinone) nanofibrils: equilibrium, kinetics, and mechanism studies. J Nanomater 2016, Article ID 7245829

[6] Hadi P, To M-H, Hui C-W, Lin CSK, McKay G (2015) Aqueous mercury adsorption by activated carbons. Water Res 73:37-55
[7] Mahmud HNME, Huqa AKO, Yahya Rb (2016) Removal of heavy metal ions from wastewater/aqueous solution by polypyrrole-based adsorbents: a review. RSC Adv 6:14778-14791

[8] Streets DG, Horowitz HM, Jacob DJ, Lu Z, Levin L, ter Schure AFH, Sunderland EM (2017) Total mercury released to the environment by human activities. Environ Sci Technol 51:5969-5977

[9] US EPA (2001) National primary drinking water standards. Report EPA 816-F-01-007, Washington DC. https://www.e pa.gov/ground-water-and-drinking-water/national-primary-d rinking-water-regulations. Accessed 10 July 2019

[10] Zhang F-S, Nriagu JO, Itoh H (2005) Mercury removal from water using activated carbons derived from organic sewage sludge. Water Res 39:389-395

[11] Kabiri S, Tran DNH, Azari S, Losic D (2015) Graphenediatom silica aerogels for efficient removal of mercury ions from water. ACS Appl Mater Interfaces 7:11815-11823

[12] Yap PL, Kabiri S, Tran DNH, Losic D (2019) Multifunctional binding chemistry on modified graphene composite for selective and highly efficient adsorption of mercury. ACS Appl Mater Interfaces 11:6350-6362

[13] Yu J-G, Yue B-Y, Wu X-W, Liu Q, Jiao F-P, Yiang X-Y, Chen X-Q (2016) Removal of mercury by adsorption: a review. Environ Sci Pollut Res 23:5056-5076

[14] Pasinszki T, Krebsz M, Kótai L, Sajó IE, Homonnay Z, Kuzmann E, Kiss LF, Váczi T, Kovács I (2015) Nanofurry magnetic carbon microspheres for separation processes and catalysis: synthesis, phase composition, and properties. J Mater Sci 50:7353-7363. https://doi.org/10.1007/s10853015-9292-6

[15] Pasinszki T, Krebsz M, Lajgut GG, Kocsis T, Kótai L, Kauthale S, Tekale S, Pawar R (2018) Copper nanoparticles grafted on carbon microspheres as novel heterogeneous catalysts and their application for the reduction of nitrophenol and one-pot multicomponent synthesis of hexahydroquinolines. New J Chem 42:1092-1098

[16] Córdoba MH, Garcia IL, Sánchez-Pedrenno C (1984) Spectrophotometric determination of mercury with thiocyanate and rhodamine B. Mikrochim Acta 3:467-475

[17] Liu L, Luo X-B, Ding L, Luo S-L (2019) Application of nanotechnology in the removal of heavy metal from water. In: Luo X, Deng F (eds) Nanomaterials for the removal of pollutants and resource reutilization. Elsevier, Amsterdam

[18] Zhang X, Scott T, Socha T, Nielsen D, Manno M, Johnson M, Yan Y, Losovyj Y, Dowben P, Aydil ES, Leighton C (2015) Phase stability and stoichiometry in thin film iron pyrite: impact on electronic transport properties. ACS Appl Mater Interfaces 7:14130-14139 
[19] Krishnan R, Jerin J, Manoj B (2013) Raman spectroscopy investigation of camphor soot: spectral analysis and structural information. Int J Electrochem Sci 8:9421-9428

[20] Walton EL, Sharp TG, Hu J, Filiberto J (2014) Heterogeneous mineral assemblages in Martian meteorite Tissint as a result of a recent small impact event on Mars. Geochim Cosmochim Acta 140:334-348

[21] Wopenka B (2012) Raman spectroscopic investigation of two grains from comet $81 \mathrm{P} /$ Wild 2: information that can be obtained beyond the presence of $\mathrm{sp}^{2}$-bonded carbon. Meteor Planet Sci 47:565-584

[22] Thommes M, Kaneko K, Neimark AV, Olivier JP, Rodriguez-Reinoso F, Rouquerol J, Sing SW (2015) Physisorption of gases, with special reference to the evaluation of surface area and pore size distribution (IUPAC Technical Report). Pure Appl Chem 87:1051-1069

[23] Scheuermann W, Ritter GJ (1969) Raman Spectra of Cinnabar $(\mathrm{HgS})$, Realgar $\left(\mathrm{As}_{4} \mathrm{~S}_{4}\right)$ and Orpiment $\left(\mathrm{As}_{2} \mathrm{~S}_{3}\right)$. Z Naturforsch 24:408-411

[24] Sun Y, Lv D, Zhou J, Zhou X, Lou Z, Baig SA, Xu X (2017) Adsorption of mercury(II) from aqueous solutions using $\mathrm{FeS}$ and pyrite: a comparative study. Chemosphere 185:452-461

[25] Sun M, Cheng G, Ge X, Chen M, Wang C, Lou L, Xu X (2018) Aqueous $\mathrm{Hg}(\mathrm{II})$ immobilization by chitosan stabilized magnetic iron sulfide nanoparticles. Sci Tot Environ 621:1074-1083

[26] Chen Y, Liang W, Li Y, Wu Y, Chen Y, Xiao W, Zhao L, Zhang J, Li H (2019) Modification, application and reaction mechanisms of nano-sized iron sulfide particles for pollutant removal from soil and water: a review. Chem Eng J 362:144-159

[27] Ting Y, His HC (2019) Iron sulfide minerals as potential active capping materials for mercury-contaminated sediment remediation: a minireview. Sustainability 11:1747
[28] Pillay K, Cukrowska EM, Coville NJ (2013) Improved uptake of mercury by sulphur-containing carbon nanotubes. Microchem J 108:124-130

[29] Abdelouahab-Reddam Z, Wahby A, Rel Mail, Silvestre-Albero J, Rodriguez-Reinoso F, Sepulveda-Escribano A (2014) Activated carbons impregnated with $\mathrm{Na}_{2} \mathrm{~S}$ and $\mathrm{H}_{2} \mathrm{SO}_{4}$ : texture, surface chemistry and application to mercury removal from aqueous solutions. Ads Sci Technol 32:101-115

[30] Zhang C, Sui J, Li J, Tang Y, Cai W (2012) Efficient removal of heavy metal ions by thiol-functionalized superparamagnetic carbon nanotubes. Chem Eng J 210:45-52

[31] Cai JH, Jia CQ (2010) Mercury removal from aqueous solution using coke-derived sulfur-impregnated activated carbons. Ind Eng Chem Res 49:2716-2721

[32] Hadavifar M, Bahramifar N, Younesi H, Li Q (2014) Adsorption of mercury ions from synthetic and real wastewater aqueous solution by functionalized multi-walled carbon nanotube with both amino and thiolated groups. Chem Eng J 237:217-228

[33] Bandaru NM, Reta N, Dalal H, Ellis AV, Shapter J, Voelcker NH (2013) Enhanced adsorption of mercury ions on thiol derivatized single wall carbon nanotubes. J Hazardous Mat 261:534-541

[34] Mohan D, Gupta VK, Srivastava SK, Chander S (2001) Kinetics of mercury adsorption from wastewater using activated carbon derived from fertilizer waste. Coll Surf A 177:169-181

Publisher's Note Springer Nature remains neutral with regard to jurisdictional claims in published maps and institutional affiliations. 